\title{
Adições crescentes de ácido fítico à dieta não interferiram na digestibilidade da caseína e no ganho de peso em ratos
}

\section{Increasing quantities of phytic acid in the diet did not affect casein digestibility and weight gain in rats}

\author{
Admar Costa de OLIVEIRA ${ }^{1}$ \\ Soely Maria Pissini Machado REIS ${ }^{1}$ \\ Érika Mirian de CARVALHO ${ }^{1}$ \\ Fernanda Motta Veiga PIM ENTA ${ }^{1}$ \\ Karina Ribeiro RIOS ${ }^{1}$ \\ Kelly Cristina PAIVA ${ }^{1}$ \\ Lucilene Maria de SOUSA ${ }^{1}$ \\ Marconi de ALMEIDA ${ }^{1}$ \\ Sandra Fernandes ARRUDA ${ }^{1}$
}

\section{RE S U M O}

0 crescente consumo de alimentos de origem vegetal, sejam como fontes protéicas com baixo teor de gordura ou como fontes de fibras, tem acrescido à dieta humana o ácido fítico. Devido à sua carga altamente negativa, 0 ácido fítico tem sido visto como componente de ação antinutricional capaz de quelar minerais bivalentes, proteínas e amido, podendo comprometer a biodisponibilidade destes nutrientes. No presente estudo investigou-se a influência da adição de ácido fítico à dieta de caseína, em concentrações iguais ou até oito vezes superiores àquelas encontradas no feijão-comum Phaseolus vulgaris, cultivar IAC-Carioca (14,7mg de ácido fítico/g feijão cru), durante período experimental de dez dias, sobre os índices nutricionais Ganho de Peso, Quociente de Eficiência da Dieta, Quociente de Eficiência Protéica Líquida, Digestibilidade Aparente e Digestibilidade Verdadeira. Trinta e seis ratos machos SPF da linhagem Wistar, recém-desmamados, divididos em grupos experimentais com seis ratos cada, foram alimentados com dieta purificada AIN-93G isenta de ácido fítico (Controle) e dietas teste AIN-93G acrescidas de 218, 436, 872 e 1744mg de ácido fítico/kg de dieta (Tratamentos). Os ganhos de peso $(\mathrm{g})$ e os índices de qualidade dietética e protéica não apresentaram diferença estatística ( $p>0,05)$, e os valores médios entre os grupos foram: Ganho de Peso: $59,5 \pm 5,0 \mathrm{~g}$; Quociente de Eficiência da Dieta: 0,39 \pm 0,01; Quociente de Eficiência Protéica Líquida: 3,64 $\pm 0,12$;

\footnotetext{
${ }^{1}$ Departamento de Planejamento Alimentar e Nutrição, Faculdade de Engenharia de Alimentos, Universidade Estadual de Campinas. Caixa Postal 6121, 13083-970, Campinas, SP, Brasil. Correspondência para/Correspondence to: A.C.OLIVEIRA.
} 
Digestibilidade A parente: $92,7 \pm 1,1 \%$ e Digestibilidade Verdadeira: $94,4 \pm 0,9 \%$. Os resultados demonstraram que nas condições experimentais utilizadas, o ácido fítico não foi capaz de alterar o valor nutritivo da caseína.

Termos de indexação: ácido fítico, caseínas, valor nutritivo, feijão-comum, ratos, dieta.

\section{A B S T R A C T}

The recent increasing consumption of vegetal origin foods, in order to obtain protein or fiber sources with low fat, has led to the presence of various amounts of phytic acid in the diet. The phytic acid has a strong negative charge and is capable of interacting with divalent minerals, protein and starch, reducing their bioavailability. In the present study, increasing quantities of phytic acid were added to the purified diet AIN-93G, more specifically 0 (Control), 218, 436, 872 and $1744 \mathrm{mg} / \mathrm{kg}$ of diet, which correspond (except the control diet) to the concentration of $14.7 \mathrm{mg}$ of phytic of acid/g of raw bean, found in the common bean (Phaseolus vulgaris, cultivar. IAC-Carioca), representing a one to eightfold increase, respectively. Thirty-six w eaning Wistar rats were fed, during an experimental period of ten days, the purified diet AIN-93G without phytic acid (Control) and the experimental diets containing the cited amounts of phytic acid per $\mathrm{kg}$ of diet (six rats per group). The Weight Gain, the Diet Efficiency Ratio and the Protein Quality Indexes Net Protein Ratio, Apparent Digestibility and True Digestibility were determined and showed no statistical difference $(p>0.05)$. The mean values among the groups were: Weight Gain: $59.5 \pm 5.0$; Diet Efficiency Ratio: $0.39 \pm 0.01$; Net Protein Ratio: $3.64 \pm 0.12$; Apparent Digestibility: $92.7 \pm 1.1 \%$ and True Digestibility: $94.4 \pm 0.9 \%$. Thus, the results showed that phytic acid did not affect the nutritive value of casein.

Index terms: phytic acid, caseins, nutritive value, common-bean, rats.

\section{N T R O D U Ç Ã O}

Com o recente aumento do consumo de alimentos de origem vegetal ricos em fibras e proteínas, como cereais e leguminosas, a alimentação humana tem sido acrescida de componentes de ação antinutricional, naturalmente associados a estes alimentos ${ }^{1}$. Um exemplo destes é o ácido fítico, que aparece em concentrações entre $0,4 \%$ e $6,4 \%$, constituindo a principal reserva de fosfato das sementes de cereais e leguminosas ${ }^{2}$. Cerca de $70,0 \%$ do fosfato está contido no ácido fítico integrado a proteínas e/ou minerais na forma de complexos ${ }^{3}$ e 75,0\% do ácido fítico está associado a componentes da fibra solúvel presente na semente ${ }^{4}$.

O feijão-comum (Phaseolus vulgaris) é uma das principais fontes protéicas da população brasileira. Porém, o ácido fítico presente, $14,7 \mathrm{mg} / \mathrm{g}$ de feijão cru no caso do cultivar
IAC-Carioca ${ }^{5}$, pode interferir na utilização de diversos componentes nutritivos da alimentação, diminuindo a biodisponibilidade de certos nutrientes, como minerais bivalentes, amido e proteínas ${ }^{6,7}$, ou provocando efeitos fisiológicos adversos como flatulência ${ }^{3}$.

A capacidade do ácido fítico, em condições naturais nos alimentos de associar-se a cátions ou proteínas deve-se à carga negativa da molécula ${ }^{8}$. Em pH levemente ácido ou neutro, os seis grupamentos fosfato da molécula de ácido fítico expõem suas 12 cargas negativas, favorecendo a complexação direta ou indireta desta molécula com cátions bivalentes ( $\mathrm{Ca}, \mathrm{Fe}$, $\mathrm{Zn}, \mathrm{Mg}, \mathrm{Cu}$ ), e também com amido, proteínas e enzimas, podendo alterar a digestibilidade e absorção destes nutrientes ${ }^{9}$. As proteínas em pH abaixo do ponto isoelétrico apresentam carga positiva, podendo associar-se diretamente ao ácido 
fítico através de ligações eletrostáticas, ou, quando carregadas negativamente, podem ligar-se indiretamente, mediadas por cátions multivalentes ${ }^{1}$. Isto reduz a digestibilidade da proteína por tornar o complexo resistente à digestão proteolítica ${ }^{4,6}$. M esmo podendo apresentar efeitos nutricionais negativos ao homem, visto que os seres humanos têm capacidade limitada para hidrolisar a molécula ${ }^{10}$, estudos têm demonstrado o ef eito benéfico deste antinutriente como agente antioxidante, coadjuvante no tratamento de diabetes e portadores de uma possível ação anticarcinogênica ${ }^{11,12}$.

O conteúdo de ácido fítico pode ser significativamente reduzido por processos como maceração ${ }^{5}$, germinação e fermentação ${ }^{13}$. A eficiência da degradação é maior nos processos que favorecem a ativação da fitase, como a fermentação e o cozimento ${ }^{14,15}$. Esta enzima hidrolisa 0 ácido fítico, produzindo inositóis com menor número de fosforilações penta-, tetra-, tri-, di- e monofosfatados, os quais, com exceção do pentafosfato, não atuam como quelante de nutrientes ${ }^{16}$

0 presente estudo teve como objetivo avaliar a influência da adição de ácido fítico em concentrações iguais e até oito vezes superiores às encontradas no feijão-comum cru Phaseolus vulgaris sobre o valor nutritivo da caseína, utilizando ratos Wistar como animais experimentais.

\section{MATERIALE MÉTODOS}

Foram utilizados 36 ratos machos SPF albinos da linhagem Wistar, entre 21-23 dias, recém-desmamados, provenientes do Centro de Bioterismo da Universidade Estadual de Campinas (Unicamp). Os animais foram pesados na chegada $(55,1 \pm 2,8 \mathrm{~g})$ e submetidos a um período de aclimatação ao ambiente em gaiolas de crescimento individuais, durante quatro dias, com dieta não purificada (Nuvital ${ }^{\circledR}$ ). A pós este período foi verificado o peso dos animais $(80,14 \pm 3,3 \mathrm{~g})$ e os mesmos foram divididos em seis grupos com seis animais cada, com a mesma média de peso corporal, e colocados em gaiolas metabólicas durante quatro dias para adaptação às dietas experimentais específicas para cada grupo. Nos dez dias seguintes transcorreu o período experimental para os cálculos do Ganho de Peso (GP) dos ratose dos índices nutricionais Quociente de Eficiência da Dieta (QED), Quociente de Eficiência Protéica Líquida (NPR), Digestibilidade Aparente (DA) e Digestibilidade Verdadeira (DV) da caseína. Determinou-se também o consumo das dietas, que foram oferecidas, assim como a água, à vontade.

As condições ambientais do Laboratório de Ensaios Biológicos eram temperatura de $22 \pm 2^{\circ} \mathrm{C}$, $50-60 \%$ de umidade relativa do ar e ciclo com alternância automática para claro/escuro de 12 horas. 0 protocolo do estudo foi previamente aprovado pela Comissão de Ética na Experimentação Animal da Unicamp.

As dietas foram preparadas segundo a formulação do American Institute of Nutrition para a dieta AIN-93G, com modificação do conteúdo protéico para $12 \%{ }^{17}$. A adição de ácido fítico às dietas foi considerada levando-se em conta os $14,7 \mathrm{mg} / \mathrm{g}$ de feijão cru, encontrados no cultivar IAC-Carioca Lote 0999, proveniente do Centro de Produção de Material Propagativo do Instituto Agronômico de Campinas, SP, sendo este teor determinado no Laboratório de Lípides da Unicamp. Foram utilizados ácido fítico solução $40 \%$ da marca Aldrich Chemical Company na forma de hexafosfato de mioinositol e caseína comercial M. Cassab com 81\% de proteína bruta. As dietas experimentais ficaram assim constituídas: dieta aprotéica (AP) para correção dos dados de NPR, sendo o teor de proteína substituído proporcionalmente por amido, amido dextrinizado e sacarose; dieta controle (C) com caseína e sem adição de ácido fítico; dieta com adição de $1,47 \mathrm{~g}$ de ácido fítico (XAF); dieta com adição de $2,9 \mathrm{~g}$ de ácido fítico $(2 \times \mathrm{AF})$; dieta com adição de 5,88g de ácido fítico (4X AF); e dieta com $11,76 \mathrm{~g}$ de ácido fítico (8x AF), sendo as adições de ácido fítico feitas por $100 \mathrm{~g}$ de caseína, 
o que correspondia às adições de $0,218,436$, 872 e $1744 \mathrm{mg}$ de ácido fítico por kg de dieta. As dietas eram isoprotéicas $(12,3 \pm 0,2 \%)$ e isoenergéticas $(391,5 \pm 2,3 \mathrm{kcal} / 100 \mathrm{~g})$.

0 consumo das dietas foi monitorado durante os dez dias do período experimental, bem como a evolução ponderal dos ratos. Os animais foram pesados durante o período experimental, com intervalos de quatro dias, em balança semi-analítica. As fezes foram coletadas no quarto dia de experimento para determinação do nitrogênio excretado. Para o cálculo da Digestibilidade Aparente e Digestibilidade Verdadeira (DA e DV), Quociente de Eficiência da Dieta (QED) e Quociente de Eficiência Protéica Líquida (NPR), seguiu-se a metodologia descrita por Pellet \& Young $(1980)^{18}$.

O teor protéico das dietas e do nitrogênio fecal foi determinado através do método semi- -micro Kjeldahl preconizado pela Association of Official Analytical Chemists ${ }^{19}$, utilizando-se o fator de conversão 6,38 para a caseína ${ }^{20}$.

Os dados obtidos foram submetidos à análise de variância ANOVA e do teste de Tukey para confronto entre as médias. O software Statistics and Tables foi utilizado ao nível de significância $p<0,05$.

\section{RES U LTA D OS E DISCUSSÃ O}

Os ratos alimentados com as dietas controle e experimentais acrescidas de ácido fítico não apresentaram diferença estatística $(p>0,05)$ com relação ao ganho de peso médio, durante os 18 dias de duração do ensaio (Figura 1). O GP médio entre os diversos tratamentos, exceto para o grupo aprotéico, foi de 59,5 $\pm 5,0 \mathrm{~g}$ para os dez dias do período experimental.

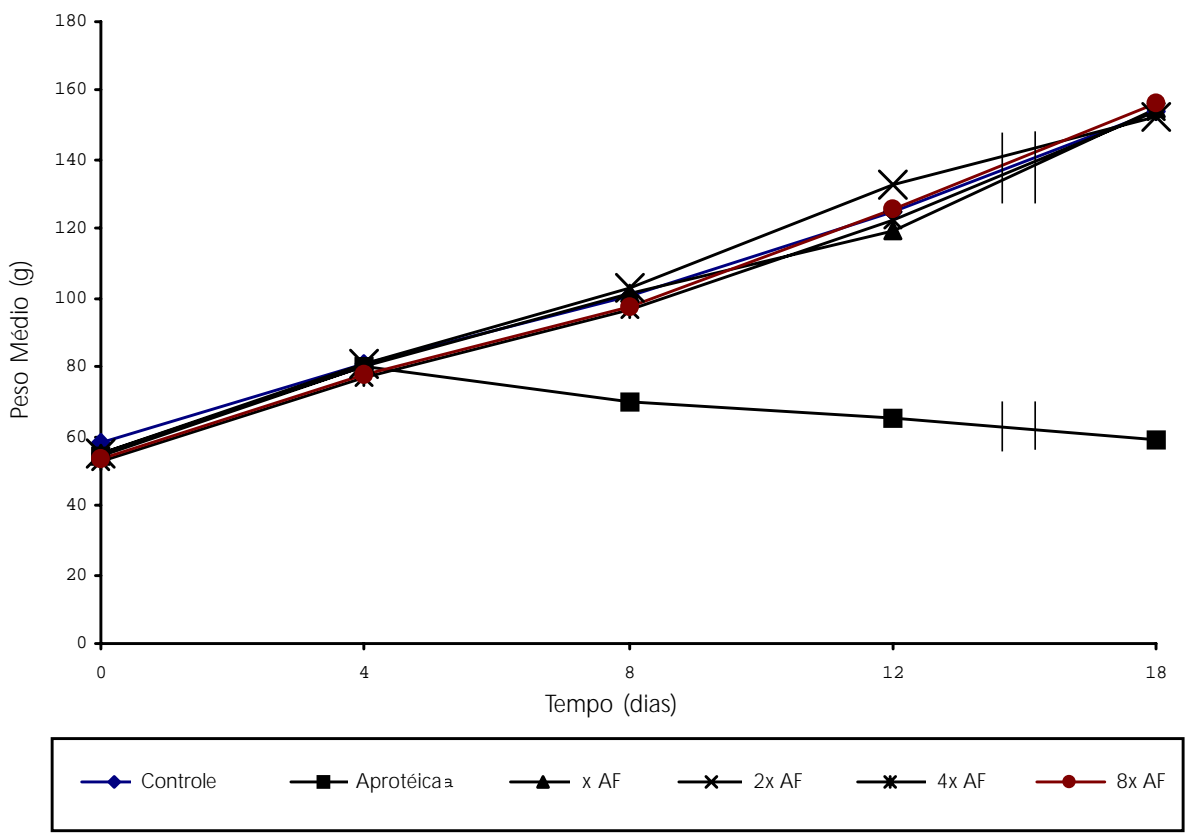

Figura 1. Evolução do peso médio dos ratos Wistar durante os 4 dias de aclimatação com dieta comercial Nuvital ${ }^{\circledR}$ (Tempo 0-4), 4 dias de adaptação às dietas experimentais (Tempo 4-8) e 10 dias de experimento (Tempo 8-18), quando submetidos aos seguintes tratamentos: Controle (AIN-93G); Aprotéica (AIN-93G, sendo o teor protéico substituído proporcionalmente por amido, amido dextrinizado e sacarose); X AF (AIN-93G acrescida de 1,47g de ácido fitico/ 100g caseína); 2X AF (AIN-93G acrescida de 2,94g de ácido fitico/ $100 \mathrm{~g}$ caseína); $4 \times$ AF (AIN-93G acrescida de 5,88 g de ácido fitico/100g caseína); 8x AF (AIN-93G acrescida de 11,76g de ácido fitico/100g caseína), correspondendo às adições de 0, 218, 436, 872 e $1744 \mathrm{mg}$ de ácido fítico por Kg de dieta. 
Tabela 1. Quociente de Eficiência da Dieta (QED), Quociente de Eficiência Líquida da Proteína (NPR), Digestibilidade Aparente (DA) e Digestibilidade Verdadeira (DV) das dietas controle (C), com adição de 1,47g de ácido fítico (X AF), 2,94g de ácido fítico (2x AF), 5,88g de ácido fítico $(4 \times A F)$ e $11,76 \mathrm{~g}$ de ácido fítico ( $8 \times \mathrm{AF})$, por $100 \mathrm{~g}$ de caseína, correspondendo às adições de $0,218,436,872$ e $1744 \mathrm{mg}$ de ácido fítico por $\mathrm{kg}$ de dieta durante o período de experimento (10 dias), utilizando ratos Wistar.

\begin{tabular}{|c|c|c|c|c|}
\hline Grupos & QED & NPR & DA & DV \\
\hline$C$ & $0,38 \pm 0,05^{a}$ & $3,60 \pm 0,39^{a}$ & $92,7 \pm 1,0^{a}$ & $94,4 \pm 1,0^{a}$ \\
\hline$x A F$ & $0,38 \pm 0,03^{a}$ & $3,71+0,22^{\mathrm{a}}$ & $91,1 \pm 3,2^{a}$ & $93,3 \pm 2,2^{a}$ \\
\hline $2 \times A F$ & $0,41 \pm 0,03^{a}$ & $3,47 \pm 0,23^{a}$ & $92,4 \pm 2,0^{a}$ & $94,0 \pm 2,0^{a}$ \\
\hline $4 \times A F$ & $0,39 \pm 0,05^{a}$ & $3,79 \pm 0,41^{a}$ & $94,1 \pm 0,8^{a}$ & $95,7 \pm 0,8^{a}$ \\
\hline $8 \times A F$ & $0,39 \pm 0,02^{a}$ & $3,65 \pm 0,14^{a}$ & $93,0 \pm 0,8^{a}$ & $94,6 \pm 0,8^{a}$ \\
\hline
\end{tabular}

(a) Médias assinaladas com a mesma letra não diferem entre si $(p>0,05)$.

Apesar de o ácido fítico ter sido adicionado às dietas em quantidade até oito vezes acima do teor encontrado no feijão cru (Phaseolus vulgaris) e agir como quelante mais em termos de absorção no trato gastrintestinal, o QED demonstrou uma conversão peso de dieta/peso corporal do rato de $38 \%$ a $41 \%$ entre as diferentes dietas, não apresentando variação significativa entre os dados (Tabela 1).

Em estudo com ratos em cuja dieta foram utilizadas diferentes leguminosas como fonte protéica, verificou-se perda de peso de aproximadamente três vezes em comparação com ratos alimentados com caseína acrescida de metionina. Os resultados foram associados à presença de ácido fítico nos grãos, resultando em um baixo valor biológico das proteínas daquelas dietas ${ }^{7}$.

Entretanto, é difícil avaliar um crescimento desfavorável dos ratos somente considerando como efeito antinutricional o ácido fítico, pois nos grãos encontram-se outros fatores antinutricionais, como polifenóis, predominantemente taninos ${ }^{12} \mathrm{e}$ inibidores de proteases que influenciam o valor nutritivo destas leguminosas; além disso, os grãos são deficientes em aminoácidos sulfurados, os quais são essenciais na síntese de proteínas ${ }^{6}$. A análise (Tabela 1) mostra que o valor nutritivo das dietas não foi afetado pela adição de ácido fítico, pois os valores do NPR não diferiram entre os tratamentos, apresentando como valor médio $3,64 \pm 0,12$. O consumo alimentar e a ingestão protéica (Tabela 2 ) reforçam esta afirmativa.
Tabela 2. Consumo de Dieta e Ingestão Protéica dos animais nas dietas controle $(C)$, com adição de $1,47 \mathrm{~g}$ de ácido fítico ( $\mathrm{XAF}$ ), 2,94g de ácido fítico (2x AF), $5,88 \mathrm{~g}$ de ácido fítico (4X AF) e $11,76 \mathrm{~g}$ de ácido fítico (8x AF), por $100 \mathrm{~g}$ de caseína, o que correspondendo às adições de $0,218,436,872$ e $1744 \mathrm{mg}$ de ácido fítico por $\mathrm{kg}$ de dieta durante o período de experimento (10 dias), utilizando ratos Wistar.

\begin{tabular}{lcc}
\hline Grupos & Consumo de Dieta (g) & Ingestão Protéica $(\mathrm{g})$ \\
\hline $\mathrm{C}$ & $146,8 \pm 5,0^{\mathrm{a}}$ & $18,0 \pm 0,6^{\mathrm{a}}$ \\
$\mathrm{xAF}$ & $146,4 \pm 19,5^{\mathrm{a}}$ & $17,8 \pm 2,4^{\mathrm{a}}$ \\
$2 \times \mathrm{AF}$ & $157,0 \pm 6,9^{\mathrm{a}}$ & $18,8 \pm 0,7^{\mathrm{a}}$ \\
$4 \times \mathrm{AF}$ & $157,7 \pm 10,1^{\mathrm{a}}$ & $18,9 \pm 1,2^{\mathrm{a}}$ \\
$8 \times \mathrm{AF}$ & $144,9 \pm 10,1^{\mathrm{a}}$ & $18,1 \pm 1,3^{\mathrm{a}}$ \\
\hline
\end{tabular}

(a) M édias assinaladas com a mesma letra não diferem entre si $(p>0,05)$.

As médias dos valores para Digestibilidade Aparente e Digestibilidade Verdadeira foram $92,7 \pm 1,1$ e $94,4 \pm 0,9$, respectivamente.

Faz-se importante salientar que a maioria dos processos de redução do ácido fítico propicia também a diminuição de outros componentes de ação antinutricional, como taninos, inibidores de proteases e oxalatos ${ }^{21,22}$. Na fermentação, por exemplo, os microorganismos podem produzir enzimas proteolíticas, também responsáveis pelo aumento da digestibilidade das proteínas ${ }^{23}$. Os trabalhos utilizando processos de redução do ácido fítico sugerem que este é um dos componentes responsáveis pela menor digestibilidade de proteínas e amido; no entanto, diversos outros fatores antinutricionais também tiveram seus teores diminuídos, podendo atuar mais expressivamente sobre a biodisponibilidade dos nutrientes que o próprio ácido fítico. 
Segundo Hurrel et al. $(1992)^{24}$, mesmo em isolados de soja onde o ácido fítico foi completamente reduzido a níveis não detectáveis, houve efeito inibitório na absorção de ferro, sugerindo que o ácido fítico não era o principal composto influenciando a biodisponibilidade de certos nutrientes. Estudos in vivo demonstraram resultados semelhantes aos obtidos neste trabalho. A adição de $5 \%$ de ácido fítico à caseína não alterou sua digestibilidade, utilização e ganho de peso em roedores ${ }^{1}$. A presença de fitase no intestino e flora bacteriana de animais pode ser outro fator justificador da não alteração da digestibilidade in vivo, ao contrário de ensaios in vitro, uma vez que esta enzima degrada o ácido fítico a inositóis com menor número de fosforilação, os quais não têm a capacidade de quelar nutrientes e, conseqüentemente, reduzir sua biodisponibilidade.

\section{O N C L U S Ã O}

Nas condições em que o presente trabalho foi desenvolvido, a adição de ácido fítico às dietas em concentrações até oito vezes superiores ao teor encontrado no feijão-comum cru (Phaseolus vulgaris), no período de experimentação de dez dias, não comprometeu a utilização da caseína pelos ratos. Ao comparar os grupos experimentais com o grupo controle, alimentado com dieta purificada, isenta de ácido fítico ou qualquer outro componente de conotação antinutricional, observou-se não haver diferença significativa $(p>0,05)$ quanto ao ganho de peso, consumo de dieta, Quociente de Eficiência da Dieta, Quociente de Eficiência Protéica Líquida, Digestibilidade A parente e Digestibilidade Verdadeira da caseína.

\section{REFERÊ NCIAS}

1. Rickard SE, Thompson LU. Interactions and biological effects of phytic acid. ACS Symposium Series 1997; 662:294-312.
2. Shamsuddin AM, Vucenik I, Cole KE. $\mathbb{I}_{6}$ : a novel anti-cancer agent. Life Sci 1997; 61(4):343-54.

3. Zhou JR, Erdman JW. Phytic acid in health and disease. Crit Rev Food Sci Nutr 1995; 35(6):495-508.

4. Torre M, Rodriguez AR, Saura-Calixto F. Effects of dietary fiber and phytic acid on mineral availability. Crit Rev Food Sci Nutr 1991; 30(1):1-22.

5. Queiroz KS, Helbig E, Reis SM PM , Carraro F, Oliveira AC. O processamento doméstico de feijão-comum ocasiona uma redução nos fatores antinutricionais fitatos e taninos e no fator de flatulência estaquiose. Livro de Resumos do 50 Congresso Nacional da Sociedade Brasileira de Alimentação e Nutrição 1999; São Paulo. São Paulo: Sociedade Brasileira de Alimentação e Nutrição; 1999. p.174.

6. Éstevez AM, Castillo-Figuerola F, Yánez E. Effect of processing on some chemical and nutritional characteristics of pre-cooked and dehydrated legumes. Plant Foods for Hum Nutr 1991; 41(3):193-201.

7. Proll J, Petzke KJ, Ezeagu IE, Metges CC. Low nutritional quality of unconventional tropical crop seeds in rats. J Nutr 1998; 128(11):2014-22.

8. Cheryan M. Phytic acid interactions in food systems. Crit Rev Food Sci Nutr 1980; 13(4):297-335.

9. Pallauf J, Rimbach G. Nutritional significance of phytic acid and phytase. Arch Animal Nutr 1997; 50(4):301-19.

10. Lönnerdal B, Sandberg A, Sandstrom B, Kunz C. Inhibitory effects of phytic acid and other inositol phosphates on zinc and calcium absorption in suckling rats. J Nutr 1989; 119(2):211-14.

11. Harland BF, M orris ER. Phytate: a good or bad food component? Nutr Res 1995; 15(5):733-53.

12. Silva MR, Silva MAAP. Aspectos nutricionais de fitatos e taninos. Rev Nutr 1999; 12(1):21-5.

13. Beal L, Mehta T. Zinc and phytate distribution in peas: influence of heat treatment germination $\mathrm{pH}$ substrate and phosphorus on pea phytase and phytase. J Food Sci 1985, 50(1):96-100. 
14. Ologhobo AD, Fetuga BL. Distribution of phosphorus and phytate in some Nigerian varieties of legumes and some effects of processing. J Food Sci 1984, 49(1):199-201.

15. Bullock JI, Duffin PA, Nolan KB. In vitro hydrolysis of phytate at $95^{\circ} \mathrm{C}$ and the influence of metal iron in the rate. J Sci Food Agric 1993; 63(2):261-63.

16. Sandberg AS, Andersson H, Kivisto B, Sandstrom $B$. Extrusion cooking of a high-fiber cereal product 1. Effects on digestibility and absorption of protein fat starch dietary fiber and phytate in the small intestine. Br J Nutr 1986; 55(2):245-54.

17. Goena M, M arzo F, Fernández-González L, Tosar A, Frühbeck $G$, Santidrián $S$. Effect of the raw legume Vicia ervilia on the muscle and liver protein metabolism in growing rats. Rev Española de Fisiol 1989; (45 Suppl):55-60.

18. Pellet PL, Young VR. Nutritional evaluation of protein foods. Tokyo: The United Nations University; 1980.

19. Association of Official Analytical Chemists. Official methods of analysis. 12th. Washington DC; 1975.
20. Food and Agriculture Organization. Amino-acid content of food and biological data on proteins. Roma; 1970. (FAO Nutritional Studies, 24).

21. Gupta M, Khetarpaul N, Chauhan BM. Rabadi fermentation of wheat: changes in phytic acid content and in vitro digestibility. Plant Foods Hum Nutr 1992; 42(2):109-16.

22. Ene-Obong HN, Obizoba IC. Effect of domestic processing on the cooking time nutrients and in vitro protein digestibility of the African yambean (Sphenostylis stenocarpa). Plant Foods Hum Nutr 1996; 49(1):43-52.

23. Hesseltine CW. The future of fermented foods. Nutr Rev 1983; 41(10):293-301.

24. Hurrel RF, Juillerat MA, Reddy MB, Lynch SR, Dassenko AS, Cook JD. Soy protein phytate and iron absorption in human. Am J Clin Nutr 1992; 56(3):573-78.

Recebido para publicação em 28 de agosto de 2001 e aceito em 6 de março de 2002. 